\title{
OBSERVACIONES AL PROFESOR TUSELL
}

\author{
JUAN VELARDE FUERTES
}

Una nota sobre un libro no se suele atiborrar de citas bibliográficas cuando éstas parecen conocidas de la comunidad científica a la que se dirigen; pero leído el texto Una crítica del profesor Velarde, del profesor Tusell, por si fuera necesario ampliar mi comentario, con mucho gusto las señalo. Sobre la cuestión Alba, desde la tesis doctoral del profesor Juan Muñoz a los trabajos sobre el Banco de Crédito Industrial, todo parece harto conocido; para eliminar el último escrúpulo de lo que subyacía, véase este párrafo de Francesc Cambó -Memòries (1876-1936), tomo 1, 3. a ed., Editorial Alpha, Barcelona, 1981, p. 375-, al referirse al general Primo de Rivera: "Què té d'estrany, doncs, que en llançar el seu Manifest contra un govern odiat y menyspreat, comptés, no sols amb la guarnició, sinó amb la simpatia de la quasi totalitat de Barcelona, que, en el Govern i sobretot en la persona de Santiago Alba, hi veia l'enemic constant de Catalunya i de totes les seves aspiracions, fossin econòmiques, fossin polítiques?"

Acerca de la cuestión Puig i Cadafalch, encájese el abrazo, lo que éste dice en las Memorias de La Veu de Catalunya, y la importancia y arrepentimiento posterior, en lo que señala - de modo clarísimo y, por supuesto, con alusión explícita a lo ocurrido en la estación-Francesc Cambó (ob. cit., pp. 377-378).

En relación con la cuestión Flores de Lemus, puede leerse en José G. Ceballos Teresí (Economia, Finanzas, Cambios. Historia Económica, Financiera y Politica de España en el siglo XX, tomo V: 1922-1926, «El Financiero», Madrid, s. f., p. 129): «Lo que no se ha dicho todavía es que, al llegar a Madrid el general Primo de Rivera, citó para entrevistarse con él a distintas personalidades con el propósito de formar un Gabinete de hombres civiles. Entre dichas personalidades figuraba el señor Flores de Lemus, a quien se confiaba la cartera de Hacienda, quien declinó en el acto el ofrecimiento, manifestando, sin embargo, ante los demás reunidos, que en su mayoría coincidieron con el ilustre economista, que un general sublevado no podía aspirar a que ningún hombre civil de alguna solvencia comprometiese su prestigio y se embarcase 
en la aventura, tuviese o no éxito y fuese o no duradera. El señor Flores de Lemus terminó aconsejando la formación de un Gobierno de generales, y sólo en vista de ello, haciéndose cargo del sólido fundamento de tales observaciones, es cuando el general Primo de Rivera se decidió a constituir el Directorio Militar.» Isabel Flores de Lemus, oralmente, me ratificó lo sucedido, pero no recordaba, tanto en esta ocasión como en otro non nato Gabinete Maura, también con Flores en Hacienda, quiénes eran los que asistieron a la reunión.

¿Y qué decir de la cuestión Suárez Inclán? A Pío Suárez Inclán le he estudiado, creo que aceptablemente bien, como consecuencia de mi puesto en la directiva de la Real Sociedad Geográfica. Por diversos motivos, me ha interesado mucho la escuela de generales geógrafos españoles, tangencialmente economistas, con gotas krausistas en mayor cantidad de lo que se puede sospechar. En Salamanca, en julio de 1987, con motivo de una reunión lusoespañola organizada por el Instituto Español de Estudios Estratégicos, algo me ocupé del asunto; mi ponencia se publicará con las restantes, por este Instituto, dentro de poco.

Por supuesto, abandono con mucho gusto todo tipo de admonición habitual en un profesor con más de cuarenta años de docencia universitaria. Dese por liquidada. Me refugié en ella para no escribir, lisa y llanamente, que el libro de Tusell, desde el punto de vista científico, era malo, y desde el gramatical lo mismo. Dicho queda.

Finalmente, y ya que se hace referencia a una obra mía, quiero señalar que es lógico que, gracias a un amplio y excelente conjunto de trabajos posteriores, algunos de sus puntos de vista tengan que ampliarse, rectificarse $o$ ratificarse sólo en parte. Así es la ciencia. De él siempre me quedará el orgullo de haber merecido el juicio que sigue de un maestro de la historia política, Jesús Pabón. En su Cambó. II. Parte Segunda: 1930-1947 (Editorial Alpha, Barcelona, 1969), se puede leer, en la página 553: «En realidad, los dos estudios más notables sobre la Dictadura pertenecen al campo de la Economía y son obra del profesor Juan Velarde Fuertes.» Luego continúa con los elogios a mi Flores de Lemus ante la economía española y mi Politica económica de la Dictadura, que no transcribo porque ya está bien de culto a la personalidad.

De lo demás del texto de Tusell, nada. Si alguien quiere saber lo que opino de ello, lea íntegro el inmortal soneto número 132 de la relación de Poemas escogidos de Francisco de Quevedo (edición, introducción y notas de José Manuel Blecua, Clásicos Castalia, Madrid, 1982), ése cuyo primer endecasílabo es: «Su colerilla tiene cualquier mosca...» 